\title{
Calcaneal lengthening using ipsilateral fibula (Q) autograft in the treatment of symptomatic pes valgus in adolescents
}

\author{
Chien-Cheng Lai ${ }^{1,2}$, Ting-Ming Wang ${ }^{3}$, Chih-Hung Chang 1,4, Jwo-Luen Pao ${ }^{1}$, Hsu-Wei Fang ${ }^{2}$, \\ Chun-Chien Chang ${ }^{1}$, Shang-Ming Lin ${ }^{5}$ and Tsung-yu Lan ${ }^{1,3,5^{*}}$
}

\begin{abstract}
Background: Evans calcaneal lengthening osteotomy is used to treat symptomatic flexible flatfoot when conservative treatment fails. Grafts such as autologous iliac bone grafts, allografts, and xenografts are implanted at the osteotomy site to lengthen the lateral column of the hindfoot. This study aimed to present the outcomes of an autologous mid-fibula bone graft used for calcaneal lengthening in symptomatic pes valgus in adolescents.
\end{abstract}

Methods: We retrospectively examined $23 \mathrm{ft}$ of 13 adolescents who underwent surgery between July 2014 and January 2018. The radiological and clinical outcomes (American Orthopaedic Foot and Ankle Society ankle-hindfoot scale scores) were assessed during a mean follow-up of 49.7 (range, 30.9-73.4) months. The mean distance of the lengthening site was measured to evaluate graft sinking or collapse. The Goldberg scoring system was used to determine the degree of union at the donor and recipient sites.

Results: The calcaneal pitch and the anteroposterior and lateral talo-first metatarsal (Meary) angles showed significant correction, from 14.4 to 19.6 ( $p<0.001)$, and from 14.5 to $4.6(p<0.001)$ and 13.5 to $8.5(p<0.001)$, respectively. The mean distance of the lengthening site showed no significant change $(p=0.203)$, suggesting no graft sinking or postoperative collapse. The lateral distal tibial angle showed no significant difference $(p=0.398)$, suggesting no postoperative ankle valgus changes. Healing of the recipient and donor sites occurred in 23 and $21 \mathrm{ft}$, respectively. The American Orthopaedic Foot and Ankle Society ankle-hindfoot scores improved significantly, from 68.0 to 98.5 $(p<0.001)$.

Conclusions: Evans calcaneal lengthening using an ipsilateral mid-fibula bone autograft resulted in significant improvement in clinical and radiological outcomes without ankle valgus deformity. Hence, it could be a treatment option for lateral column calcaneal lengthening in adolescents.

Keywords: Flexible flatfoot, Evans calcaneal lengthening, Ipsilateral mid-fibula bone autograft

\section{Background}

Pes planovalgus is described as a low or absent medial longitudinal arch with the hindfoot in excess valgus alignment and forefoot abduction [1]. Flexible pes

\footnotetext{
*Correspondence: gbwsh0130@gmail.com

1 Department of Orthopedic Surgery, Far Eastern Memorial Hospital, No. 21, Sec. 2, Nanya S. Rd., New Taipei City 220, Taiwan
}

Full list of author information is available at the end of the article planovalgus refers to the ability of the subtalar joint and longitudinal arch to reverse the alignment. Flexible flatfoot is common in children and usually diminishes with age, and those affected are mostly asymptomatic [2]. Symptomatic flatfoot may present with pain in the sinus tarsi or plantar medial aspect of the midfoot [1, 2]. Most children and adolescents with flexible flatfoot do not require intervention. The indications for surgery include

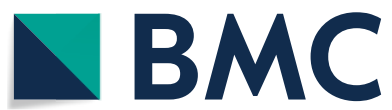

(c) The Author(s) 2021. Open Access This article is licensed under a Creative Commons Attribution 4.0 International License, which permits use, sharing, adaptation, distribution and reproduction in any medium or format, as long as you give appropriate credit to the original author(s) and the source, provide a link to the Creative Commons licence, and indicate if changes were made. The images or other third party material in this article are included in the article's Creative Commons licence, unless indicated otherwise in a credit line to the material. If material is not included in the article's Creative Commons licence and your intended use is not permitted by statutory regulation or exceeds the permitted use, you will need to obtain permission directly from the copyright holder. To view a copy of this licence, visit http://creativecommons.org/licenses/by/4.0/. The Creative Commons Public Domain Dedication waiver (http://creativecommons.org/publicdomain/zero/1.0/) applies to the data made available in this article, unless otherwise stated in a credit line to the data. 
failure of conservative treatment and intractable pain [1, 3]. Operative interventions include osteotomies, arthrodesis, arthroereisis, and soft tissue procedures [1-5].

Evans calcaneal lengthening osteotomy, which was modified by Mosca, has been used to treat symptomatic pes planovalgus $[3,5,6]$. It realigns the foot by lengthening the lateral column and allowing further bone growth. Lateral column lengthening in adolescents with pes planovalgus has good radiological and clinical outcomes, with high patient satisfaction [7]. Graft selection includes autologous iliac bone grafts (AIBG), allografts, and xenografts. The disadvantages of allografts are the lack of osteoinductive and osteogenic properties that may lead to non-union, risk of disease transmission $[8,9]$, and allograft bone failure [10]. However, in anterior cervical discectomy and fusion, studies have reported the successful use of fibular allografts and instrumentation with acceptable rates of fusion and less postoperative pain $[9,11,12]$. Autologous bone grafts have good osteoinductive and osteogenic characteristics. However, donor site morbidity of AIBG remains a major concern. Studies have shown that non-vascularized autologous fibular grafts used in the reconstruction of bone defects and treatment of nonunion of long bones in pediatric patients is a good option $[13,14]$. To the best of our knowledge, no study has described the use of autologous mid-fibula bone grafts in Evans calcaneal lengthening.

This study aimed to present the clinical and radiological outcomes, including the degree of autograft incorporation and donor site union, using ipsilateral mid-fibula autograft in adolescents with pes planovalgus.

\section{Materials and methods}

From July 2014 to January 2018, medical records were obtained and retrospectively examined after approval by the institutional review board of our hospital. The inclusion criteria were skeletally immature adolescents and patients with flexible pes planovalgus who were treated conservatively for at least 1 year before surgery. Exclusion criteria were rigid pes planovalgus, cerebral palsy, and endocrine and metabolic diseases. Information regarding the patients' sex, age at the time of surgery, body mass index (BMI), affected side (right, left, or bilateral), and length of follow-up were obtained by reviewing the medical records.

\section{Surgical technique}

Initially, gastrocnemius release was performed in the musculotendinous junction of the gastrocnemius, as described by Strayer [15], with the patient in the supine position under general anesthesia. The fascial part of the gastrocnemius was released from the medial to the lateral direction. Modified Evans calcaneal lengthening osteotomy, as described by Mosca, was performed by a senior pediatric orthopedic surgeon. A calcaneocuboid (C-C) joint was identified. A 4-cm skin incision was made over the anterolateral region of the distal calcaneus. Dissection was performed, and the sural nerve was protected. Z-lengthening was performed for the peroneus brevis tendon. The $\mathrm{C}-\mathrm{C}$ joint was temporarily fixed using a K-wire to prevent $\mathrm{C}-\mathrm{C}$ joint subluxation. The probe was inserted over the dorsal surface of the calcaneus to explore the interval between the anterior and middle facets, and osteotomy was performed through the interfacet interval. The osteotomy was performed $1-1.5 \mathrm{~cm}$ proximal to the $\mathrm{C}-\mathrm{C}$ joint in the anterolateral distal calcaneus. A surgical elevator was inserted in the osteotomy site, and the distal calcaneus fragment $(\mathrm{dCF})$ was raised to correct the abduction of the forefoot. The degree of lengthening under fluoroscopy could be used as a reference for the degree of correction of forefoot abduction.

A 5-cm skin incision was made over the mid-lateral ipsilateral leg. Dissection was carried out, followed by splitting of the deep fascia. After the deep fascia was split, dissection was performed along the posterior intermuscular septum to avoid injury to the superficial peroneal nerve. This nerve is usually located over the anterior intermuscular septum. The fibula was encountered after the periosteal elevation. The autologous bone graft was harvested from the mid-third ipsilateral fibula and was approximately $1 \mathrm{~cm}$ in length and trapezoid in shape (Fig. 1A, B), depending on the degree of correction of forefoot abduction. Two types of saws were used for autograft harvesting: Safedge ${ }^{\mathrm{TM}}$ Precision Thin (Stryker, NJ, USA) and an oscillator blade (ConMed, NY, USA). Normal saline cooling was performed when the midfibula was sawed. The bone defect of the fibula was filled with a synthetic bone graft substitute, BICERA ${ }^{\mathrm{TM}}$ (Hannox International Corp., Taipei City, Taiwan), composed of hydroxyapatite $(60 \%)$ and $\beta$-tricalcium phosphate $(40 \%)$. The deep fascia of the lateral compartment muscle from the harvest site was closed. The trapezoid-shaped bone graft was impacted to the osteotomy site with the long side of the graft facing the lateral border of the foot. The orientation of the bone graft at the osteotomy site is shown in the AP (Fig. 1C) and lateral views (Fig. 1D). Supplemental 0.062" K-wires or a pre-contoured locking plate $\left(\right.$ DARCO $^{\mathrm{TM}}$, Wright Medical Technology, TN, USA) fixation was used for stability. The processing of the harvested bone graft and graft size are shown in Fig. 1E and F, respectively. Postoperatively, the foot was protected with a short leg cast with 2 weeks of non-weight bearing and progression to full weight bearing for 4 weeks. After 4 weeks, the cast was removed, and full weight bearing was allowed in normal shoes. Sports activities were allowed after radiographic evidence of bone union. 


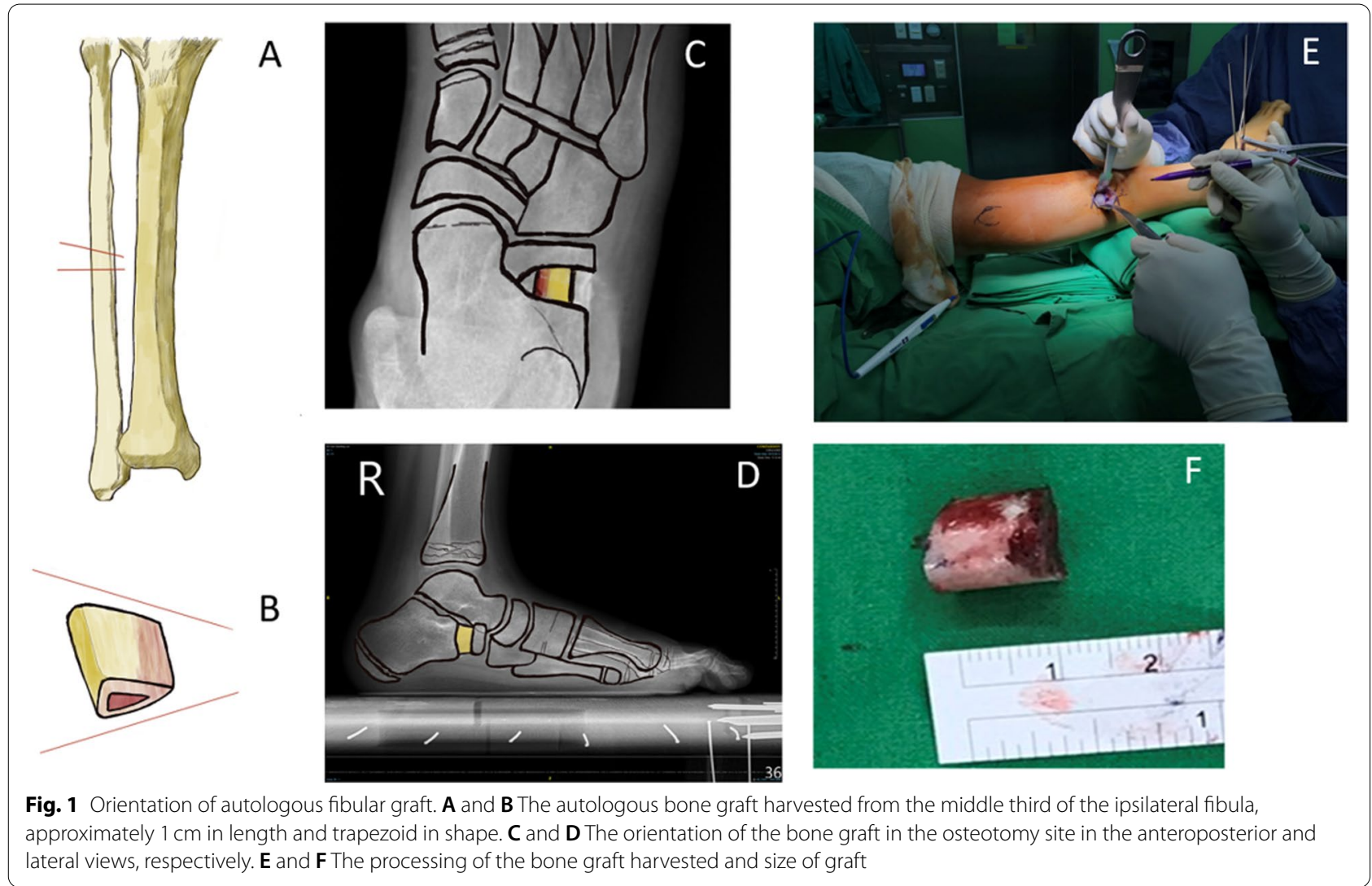

\section{Radiographic and clinical function evaluation}

Radiographic foot radiographs were obtained using a UT2000 X-ray machine (Philips Research, Eindhoven, Netherlands). All radiographic images were digitally acquired, and radiographic indices were measured using Universal Viewer Zero Footprint ${ }^{\circledR}$ software (GE Healthcare, Barrington, IL, USA). Foot alignment was evaluated by measuring the weight-bearing lateral calcaneal pitch, AP and lateral Meary (talo-first metatarsal) angle, and lateral distal tibial angle (LDTA) (Fig. 1) at 1, 3, 12, and 24 months postoperatively. The LDTA was used to evaluate valgus deformity of the ankle. A small lateral talofirst metatarsal (T-1st MT; Meary) angle indicates less pes planus of the midfoot; a small AP T-1st MT (Meary) angle indicates less abduction of the forefoot and hindfoot. All radiographs were taken using standardized procedures per the guidelines outlined in the textbook of radiology [16]. The normal values of these angles are as follows: weight-bearing lateral calcaneal pitch, $25^{\circ}(2 \mathrm{SD}$ range, $15^{\circ}$ to $\left.30^{\circ}\right)$; AP Meary angle, $10^{\circ}(2 \mathrm{SD}$ range, -10 ${ }^{\circ}$ to $20^{\circ}$ ), and lateral Meary angle, $5^{\circ}\left(2 \mathrm{SD}\right.$ range, $-7{ }^{\circ}$ to $20^{\circ}$ ) [17]. The normal LDTA range is $86-92^{\circ}$ [18]. The fibula donor site and calcaneus lengthening site were also evaluated to examine the degree of union by AP scanography and lateral radiography of the ankle, respectively. All radiographic measurements were performed by three of the authors to assess the interobserver reliability.

The union of the bone graft substitute to the ipsilateral fibula and the autologous bone graft to the calcaneal osteotomy site were evaluated using the Goldberg scoring system, and three categories were chosen $[10,19]$. On AP scanography radiographs, the first category evaluates the graft appearance, which gets a score of 0 for resorbed, 1 for mostly resorbed, 2 for largely intact, and 3 for reorganized. The second and third categories evaluated bony union, which received a score of 0 for non-union, 1 for possible union, and 2 for radiographic union at the proximal and distal ends of the graft, respectively. A score lower than 6 at 9 months after surgery was defined as radiographic graft non-union; the highest possible score was 7 points, which represented graft incorporation with excellent reorganization of the graft [10].

The lengthening distance of the calcaneal osteotomy site, where an autologous fibula graft was inserted, was measured using AP and lateral radiographs of the standing foot. Distance $\alpha$ and $\beta$ represent the longest distance between the distal(dCF) and proximal calcaneal fragments ( $\mathrm{pCF}$ ) under $\mathrm{AP}$ and lateral views, respectively 
(Fig. 1). The mean distance (MD) of lengthening was defined by the following equation: $M D=(\alpha+\beta) / 2$. Greater MD shortening may indicate graft collapse or graft sinking into the calcaneus [10, 20].

Clinical outcomes were evaluated using the American Orthopaedic Foot and Ankle Society (AOFAS) anklehindfoot scale preoperatively and at 12 and 24 months postoperatively. The scoring system consists of nine domains under three different categories-pain, function, and alignment-with a total of 100 points. The visual analogue scale (VAS) was used to assess the ipsilateral fibula donor site at 12 and 24 months postoperatively.

All statistical analyses were performed using SigmaPlot 14.0 ${ }^{\circledR}$ (Systat Software Inc., CA, USA). One-way ANOVA and post hoc Bonferroni tests were used to investigate the statistically significant differences between the paired data. Statistical significance was set at $P<0.05$.

\section{Results}

A total of $25 \mathrm{ft}$ of 15 teenagers were operated during this period. Two feet of two patients were excluded: one because of rigid flat foot and one because of cerebral palsy. A total of $23 \mathrm{ft}$ of 13 teenagers (nine boys and four girls), with a mean age of 12.3 (range, 11-16) years were included in the study. The mean follow-up was 49.7 (range, 30.9-73.4) months. The mean BMI was 23.6 (range, $14.7-35.3$ ) kg/m². Ten patients underwent calcaneal lengthening of the other foot after 7.3 (range,
2.8-11.8) months. K-wire fixation was performed in $4 \mathrm{ft}$, and locking plate fixation was performed in $19 \mathrm{ft}$.

\section{Radiographic measurements}

Significant improvement was found in the calcaneal pitch, lateral Meary angle, and AP Meary angle at 1, 3, 12, and 24 months postoperatively compared with those preoperatively (Fig. 2). At the 24-month follow-up, a significant increase of $5.2^{\circ}$ in the calcaneal pitch, a significant decrease of $5.2^{\circ}$ in the lateral T-1st MT angle, and a significant decrease of $9.8^{\circ}$ in the AP T-1st MT angle was observed (Table 1). No statistical significance was observed in the LDTA at 12 and 24 months postoperatively, suggesting no ankle valgus deformity in radiographic measurements (Table 1).

The MD of the lengthening site was measured, and no significant difference was observed at 3,12 , and 24 months compared with 1 month postoperatively $(p=0.203)$ (Table 2). These findings suggest no graft sinking into the calcaneus or graft collapse at 3, 12 and 24 months postoperatively.

\section{Clinical outcomes and complications}

The AOFAS ankle-hindfoot scale was used to evaluate clinical outcomes. Significant improvements were observed at 12 and 24 months postoperatively. The scores increased from 68.0 to 97.0 and 98.5 at 12 and 24 months, respectively. The VAS scores for the ipsilateral fibula donor site were both zero at 12 and 24 months.

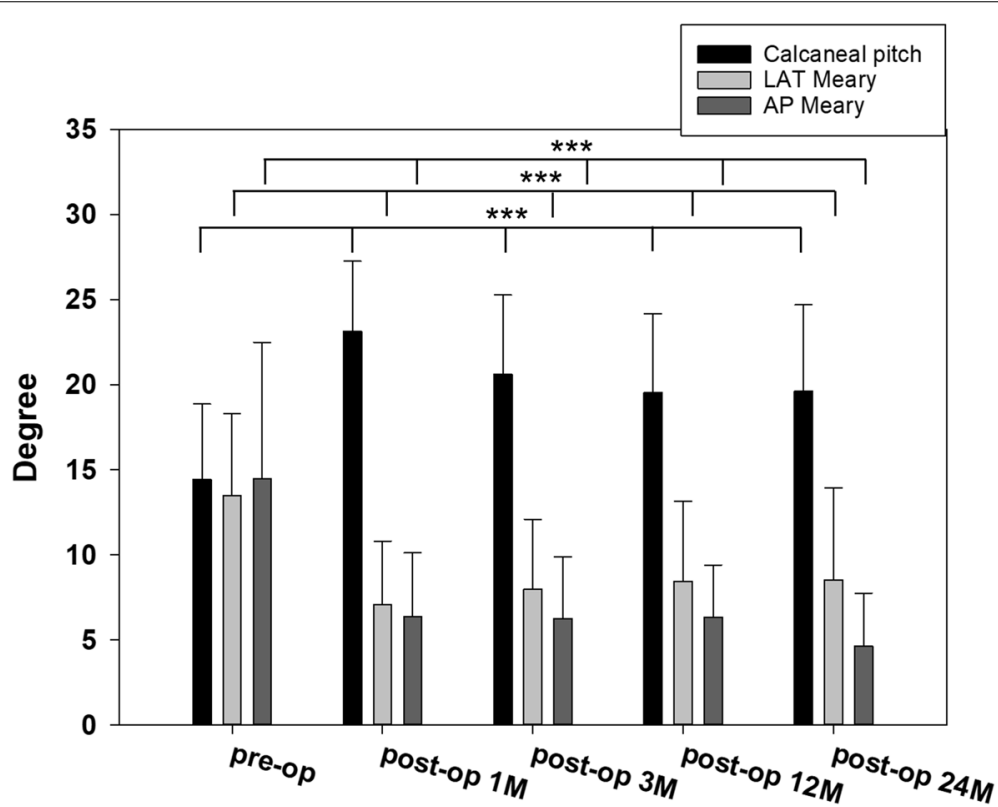

Fig. 2 Radiographic measures of preoperative and postoperative. Significant improvement after the operation AP, anteroposterior; LAT, lateral; M, months ${ }^{*} p<0.05,{ }^{* *} p<0.01,{ }^{* * *} p<0.001$ vs. pre-op group 
Table 1 Summary of radiographic measures

\begin{tabular}{|c|c|c|c|c|c|}
\hline & $\begin{array}{l}\text { Mean pre-op } \\
(\text { Mean } \pm \text { SD) }\end{array}$ & $\begin{array}{l}\text { Mean } 12 \mathrm{M} \text { postoperative } \\
\text { (Mean } \pm \text { SD) }\end{array}$ & $P$ value & $\begin{array}{l}\text { Mean } 24 \mathrm{M} \text { postoperative } \\
\text { (Mean } \pm \text { SD) }\end{array}$ & $P$ value \\
\hline Calcaneal pitch & $14.4 \pm 4.4$ & $19.5 \pm 4.6$ & $<0.001$ & $19.6 \pm 5.1$ & $<0.001$ \\
\hline LAT Meary & $13.5 \pm 4.8$ & $8.4 \pm 4.7$ & $<0.001$ & $8.5 \pm 5.4$ & $<0.001$ \\
\hline AP Meary & $14.5 \pm 8.0$ & $4.3 \pm 3.1$ & $<0.001$ & $4.6 \pm 3.1$ & $<0.001$ \\
\hline LDTA & $89.5 \pm 1.9$ & $89.1 \pm 1.8$ & 0.398 & $88.7 \pm 1.9$ & 0.398 \\
\hline
\end{tabular}

Meary angle indicates talo-first metatarsal angle

Abbreviations: LAT Lateral, AP Anteroposterior, LDTA Lateral distal tibial angle, $M$ Month

${ }^{*} p<0.05,{ }^{* *} p<0.01,{ }^{* * *} p<0.001$ vs. pre-op group

Table 2 Mean distance of the lengthening site

\begin{tabular}{lccccc}
\hline & $\begin{array}{l}\text { Postop 1 M } \\
(\text { Mean } \pm \text { SD) }\end{array}$ & $\begin{array}{l}\text { Postop 3 M } \\
(\text { Mean } \pm \text { SD) }\end{array}$ & $\begin{array}{l}\text { Postop 12M } \\
(\text { Mean } \pm \text { SD) }\end{array}$ & $\begin{array}{l}\text { Postop 24M } \\
(\text { Mean } \pm \text { SD) }\end{array}$ & P value \\
\hline $\begin{array}{l}\text { Mean } \\
\begin{array}{l}\text { Distance } \\
(\mathrm{cm})\end{array}\end{array}$ & $0.9 \pm 0.12$ & $0.85 \pm 0.12$ & $0.83 \pm 0.10$ & $0.86 \pm 0.10$ & 0.203 \\
\hline
\end{tabular}

Abbreviation: $M$ Month

${ }^{*} p<0.05,{ }^{* *} p<0.01,{ }^{* * *} p<0.001$ vs. Postop $1 \mathrm{M}$ group
Calcaneal lengthening osteotomy with autologous bone grafting was union in all patients (100\%) with mean union time of 2.5 (range, 2.3-3.2) months. The average union time at the ipsilateral fibula autograft donor site was 3.9 (range, 3.2-5.1) months postoperatively, and the union rate was $86.9 \%$ at the final follow-up. Figure 3 shows a typical example of this.

Patient 6 (a 13-year-old girl) had asymptomatic nonunion at the bilateral mid-fibula donor site. Patient 2 had a superficial wound infection in one foot 2 weeks after the operation, which resolved after 1 week of oral antibiotics. No other complications, such as calcaneal cuboid joint subluxation, were noted.

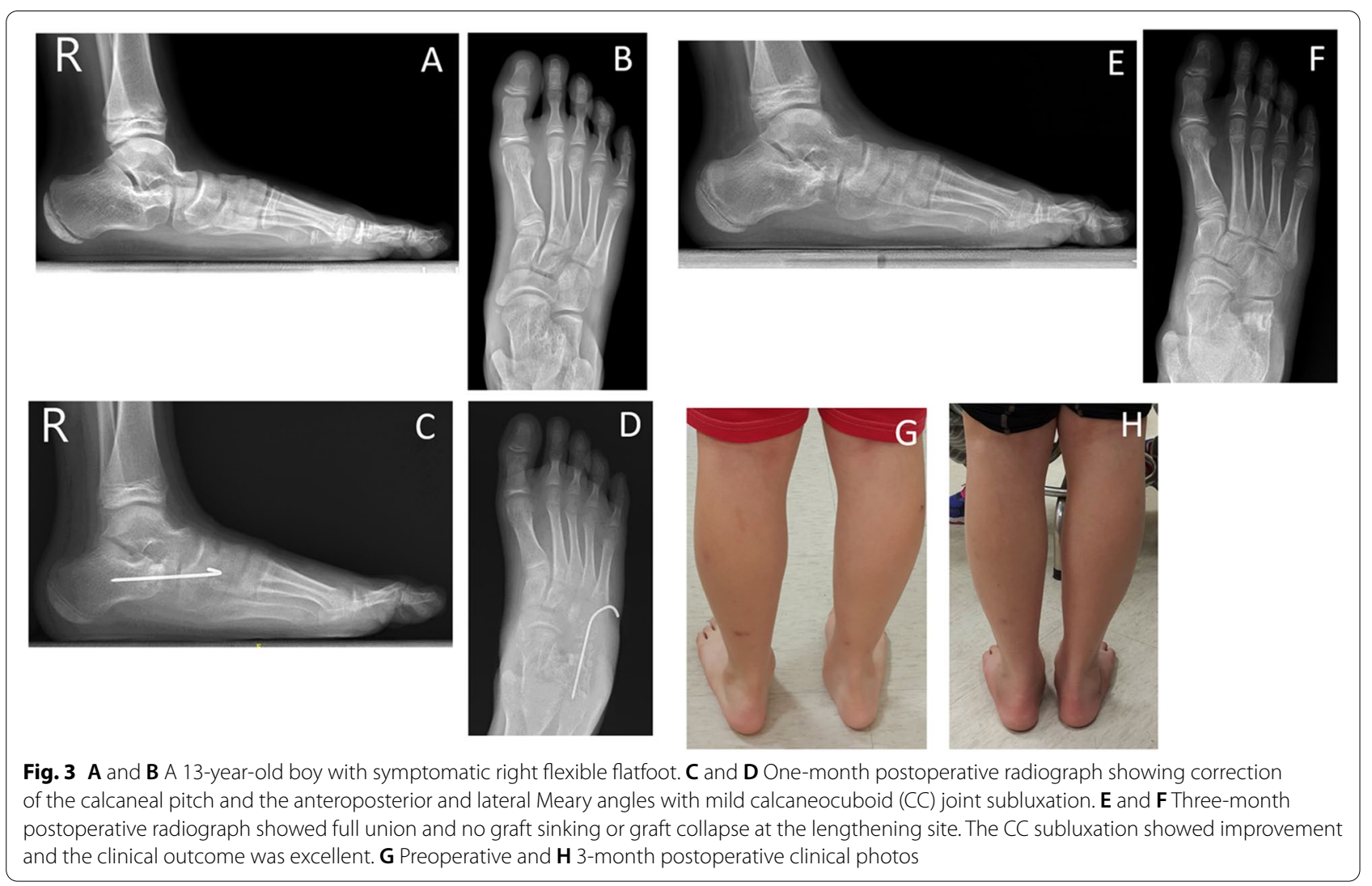




\section{Discussion}

The lateral column lengthening technique corrects hindfoot and midfoot deformity and reorientation and localization of the sustentaculum tali to lift the talonavicular joint. A systematic review reported good clinical and radiological results in the medium term, with high patient satisfaction and an acceptable level of complications [7]. However, complications associated with the technique were noted, including nonunion of the osteotomy, dorsal displacement of the anterior calcaneal tuberosity, calcaneocuboid subluxation, overcorrection, undercorrection, relapse of deformity, and injury of the sural nerve and peroneal tendon $[7,21]$. Lateral column lengthening has been shown to increase lateral plantar pressure and may be associated with lateral-side foot pain. Lateral plantar foot pain has been reported in 8 to $45 \%$ of patients [22, 23]. Pedobarometry studies have shown lateralization of the center of pressure over the hindfoot and midfoot [24]. After lengthening, the increased lateral plantar pressure was measured [25]. In our study, no lateral-side foot pain was observed. Osteoarthritis of the adjacent joints, including the calcaneocuboid and talonavicular joints, was also not found at the final follow-up.

Variants of the original technique, such as Z-osteotomy and double calcaneal osteotomy with minimally invasive surgery, have been reported to minimize complications $[26,27]$. However, studies have investigated the incidence and risk factors of allograft bone failure after calcaneal lengthening. The risk of radiographic graft failure, as determined by the Goldberg score, was found to increase with age [28]. Other factors such as sex, affected side of the body (right or left), and ambulatory status were not associated with the Goldberg score. The choice of graft plays an important role in calcaneal lengthening.

Autografts, allografts, and xenografts have been used for calcaneal lengthening osteotomy in the treatment of symptomatic pes planovalgus. Evan used tricortical bone taken from the tibia [29], while AIBG has been used more widely when choosing autologous bone grafts in recent years. A local tricortical autograft obtained from the extra-articular part of the calcaneus was recently reported [30]. Structural bone allografts, including the tricortical iliac crest and patellar and fresh-frozen structural allografts have also been used for calcaneal lengthening $[5,7,10,31,32]$. A systematic review reported that structural allografts appear to be at least non-inferior to autologous grafts with respect to the odds of union in hindfoot surgery [33]. However, this systematic review included 10 articles, including adults and children, and most studies have reported hindfoot arthrodesis surgeries. Moreover, there may be some concerns regarding mechanical strength during the processing of allografts, which may result in graft collapse and flatfoot recurrence [34, 35]. The rate of radiographic graft failure using the Goldberg score was 4 , and $1 \%$ of all patients underwent reoperation [10].

The Goldberg scoring system has been used for frozen bone allograft incorporation [19]. Although computed tomography is a better method for evaluating graft incorporation, it is not covered by the national health insurance in the authors' country. Therefore, we used the Goldberg scoring system for the incorporation of autologous bone and bone graft substitutes.

Many studies have compared autografts and allografts with different results and complications [32, 3639]. Autologous cortical bone grafts are incorporated quickly owing to their superior osteoinductivity, osteoconductivity, and biomechanical resistance [39-42]. However, harvesting autologous bone grafts may cause donor-site morbidity. A recent prospective study investigated donor site morbidity after anterior iliac crest bone grafting in 33 children and adolescents (34 hips) [43]. A visual analogue scale score was used to differentiate between the pain at the donor site and that at the recipient site, and a positive correlation was established between the measurements. Pain from autograft harvest was more intense in patients who underwent flatfoot surgery than in those who underwent other corrective osteotomies [20,43]. In our series, there was no graft collapse, recurrence of flatfoot, and no complaints of donor site pain at the final follow-up.

In weight bearing, the fibula contributes to ankle stability and transmits approximately $17 \%$ of the axial load [44]. In previous case-series studies, mid-fibula resection did not cause a biomechanical disturbance in gait and ankle instability $[45,46]$. However, donor site morbidity following fibular resection has been reported, including pain, perceived weakness, perceived instability, and paresthesia [46, 47]. In our study, approximately $1 \times 1 \times 1 \mathrm{~cm}$ trapezoidal grafts were harvested from the mid-fibula, and bone graft substitutes composed of hydroxyapatite $(60 \%)$ and $\beta$-tricalcium phosphate $(40 \%)$ were implanted into the defect. The clinical outcomes were evaluated using the AOFAS ankle-hindfoot scale and were satisfactory at 12 and 24 months of followup. The stability domain of the AOFAS ankle-hindfoot scale score was full. Graft subsidence or collapse was not observed in the present study. AP standing scanography also showed no ankle valgus at the final follow-up. However, in our case series, a 13-year-old girl presented with asymptomatic nonunion at the bilateral mid-fibula donor site. Her BMI was $18.7 \mathrm{~kg} / \mathrm{m}^{2}$, and she had no endocrine or metabolic diseases. She scored 100 points on the AOFAS hindfoot scale at the final follow-up. Pain, 
perceived weakness, ankle instability, or paresthesia was not observed.

In our study, we used a mid-fibula autograft for calcaneal lengthening. At 1 month postoperatively, the foot radiography of all patients showed some graft incorporation over the lengthening site according to the Goldberg scoring system. Therefore, we allowed full weight bearing at 1 month postoperatively.

To our knowledge, no study has described the use of autologous mid-fibula bone grafts for calcaneal lengthening in symptomatic pes valgus in adolescents. The AIBG and allografts are widely used. However, resorption followed by allograft collapse is also a disadvantage, and revision surgery may be needed later. The reported donor site morbidity and more intense pain when harvesting AIBG are the main concerns. Therefore, ipsilateral fibula cortical autograft could be another choice for calcaneal lengthening surgery.

This study had the following limitations: no control group, small number of patients, shorter follow-up duration, and no kinematic analysis. Our study also lacked clinical measures. A systematic review showed that foot posture index - Six item version (FPI - 6), Staheli arch index or Chippaux-Smirak index, may be the preferred methods of paediatric foot posture measurement [48]. Further investigations and long-term follow-up are required to demonstrate its efficacy.

\section{Conclusion}

Evans calcaneal lengthening using an ipsilateral mid-fibula bone autograft resulted in significant improvement in clinical and radiological outcomes without ankle valgus deformity. Hence, it could be a treatment option for lateral column calcaneal lengthening in adolescents.

\section{Abbreviations}

AP: Anteroposterior; MD: Mean distance; BMI: Body mass index; AIBG: Autologous iliac bone graft; AOFAS: American Orthopaedic Foot and Ankle Society; T-1st MT: Talo-first metatarsal; LDTA: Lateral distal tibial angle; C-C joint: Calcaneocuboid joint; SD: Standard deviation; dCF: Distal calcaneus fragment; pCF: Proximal calcaneus fragment.

\section{Acknowledgements}

The authors thank all the staff involved in the study at the Far Eastern Memorial Hospital, National Taiwan University Hospital, Yuan Ze University, and National Taipei University of Technology.

\section{Authors' contributions}

$\mathrm{CCL}$ was the first author to perform data acquisition, measurements, and analysis, and is involved in the conception and design of the study. TMW, CHC, $J L P, H W F, C C C$, and SML performed the data acquisition, measurements, and analysis and were involved in the conception and design of the study. TYL performed the surgical data acquisition, measurements, and analysis. He was involved in the conception and design of the study. All authors reviewed the draft manuscript and approved the final version prior to submission.

\section{Funding}

No funding was received for this research.

\section{Availability of data and materials}

The data used and analyzed during the current study are available from the corresponding author upon reasonable request.

\section{Declarations}

\section{Ethics approval and consent to participate}

The study was approved by the Research Ethics Review Committee of Far Eastern Memorial Hospital (FEMHI-IRB number: 109115-E). All methods were carried out in accordance with relevant guidelines and regulations and a sentence confirming that informed consent was obtained from all parents and/or legal guardians.

\section{Consent for publication}

Not applicable.

\section{Competing interests}

The authors declare no competing financial interests.

\section{Author details}

${ }^{1}$ Department of Orthopedic Surgery, Far Eastern Memorial Hospital, No. 21, Sec. 2, Nanya S. Rd., New Taipei City 220, Taiwan. ${ }^{2}$ Department of Chemical Engineering and Biotechnology, National Taipei University of Technology, Taipei, Taiwan. ${ }^{3}$ Department of Orthopedic Surgery, School of Medicine, National Taiwan University Hospital, Taipei, Taiwan. ${ }^{4}$ Graduate School of Biotechnology and Bioengineering, Yuan Ze University, Taoyuan, Taiwan. ${ }^{5}$ Department of Materials and Textiles, Asia Eastern University of Science and Technology, New Taipei City, Taiwan.

Received: 13 August 2021 Accepted: 8 November 2021

Published online: 23 November 2021

\section{References}

1. Bouchard M, Mosca VS. Flatfoot deformity in children and adolescents: surgical indications and management. J Am Acad Orthop Surg. 2014;22(10):623-32

2. Moraleda L, Salcedo M, Bastrom TP, Wenger DR, Albinana J, Mubarak SJ. Comparison of the calcaneo-cuboid-cuneiform osteotomies and the calcaneal lengthening osteotomy in the surgical treatment of symptomatic flexible flatfoot. J Pediatr Orthop. 2012;32(8):821-9.

3. Mosca VS. Flexible flatfoot in children and adolescents. J Child Orthop. 2010;4(2):107-21.

4. Evans AM, Rome K. A Cochrane review of the evidence for non-surgical interventions for flexible pediatric flat feet. Eur J Phys Rehabil Med. 2011:47(1):69-89.

5. Mosca VS. Calcaneal lengthening for valgus deformity of the hindfoot. Results in children who had severe, symptomatic flatfoot and skewfoot. J Bone Joint Surg Am. 1995;77(4):500-12.

6. Lee MS, Vanore $\mathrm{JV}$, Thomas $\mathrm{JL}$, et al. Diagnosis and treatment of adult flatfoot. J Foot Ankle Surg. 2005;44(2):78-113.

7. Kumar S, Sonanis SV. Lateral column lengthening for adolescent idiopathic pes planovalgus deformity - systematic review. J Orthop. 2017;14(4):571-6.

8. Khan SN, Sandhu HS, Parvataneni HK, Girardi FP, Cammisa FP Jr. Bone graft substitutes in spine surgery. Bull Hosp Jt Dis. 2000;59(1):5-10.

9. Wigfield CC, Nelson RJ. Nonautologous interbody fusion materials in cervical spine surgery: how strong is the evidence to justify their use? Spine (Phila Pa 1976). 2001;26(6):687-94.

10. Lee IH, Chung CY, Lee KM, et al. Incidence and risk factors of allograft bone failure after calcaneal lengthening. Clin Orthop Relat Res. 2015;473(5):1765-74.

11. Ryu SI, Lim JT, Kim SM, Paterno J, Willenberg R, Kim DH. Comparison of the biomechanical stability of dense cancellous allograft with tricortical iliac autograft and fibular allograft for cervical interbody fusion. Eur Spine J. 2006;15(9):1339-45.

12. Shapiro S, Connolly P, Donnaldson J, Abel T. Cadaveric fibula, locking plate, and allogeneic bone matrix for anterior cervical fusions after 
cervical discectomy for radiculopathy or myelopathy. J Neurosurg. 2001;95(Suppl 1):43-50.

13. Swamy MKS, Rathi A, Gupta V. Results of non-vascularised fibular grafting in gap non-union of long bones in paediatric age group. J Clin Orthop Trauma. 2013;4(4):180-4.

14. Liu S, Tao S, Tan J, Xiang H, Liu H, Li Z. Long-term follow-up of fibular graft for the reconstruction of bone defects. Medicine (Baltimore). 2018;97(40):e12605.

15. Pinney SJ, Sangeorzan BJ, Hansen ST Jr. Surgical anatomy of the gastrocnemius recession (Strayer procedure). Foot Ankle Int. 2004;25(4):247-50

16. McQuillen-Martensen K. Radiographic critique. 1st ed; 1995. p. 221-3.

17. Vanderwilde R, Staheli LT, Chew DE, Malagon V. Measurements on radiographs of the foot in normal infants and children. J Bone Joint Surg Am. 1988;70(3):407-15.

18. Stevens PM, Belle RM. Screw epiphysiodesis for ankle valgus. J Pediatr Orthop. 1997;17(1):9-12.

19. Goldberg VM, Powell A, Shaffer JW, Zika J, Bos GD, Heiple KG. Bone grafting: role of histocompatibility in transplantation. J Orthop Res. 1985;3(4):389-404.

20. Martinkevich P, Rahbek O, Stilling M, Pedersen LK, Gottliebsen M, Søballe $\mathrm{K}$, et al. Is structural hydroxyapatite tricalcium-phosphate graft or tricortical iliac crest autograft better for calcaneal lengthening osteotomy in childhood? Interim results from a randomised, controlled non-inferiority study. Bone Joint J. 2016;98-B(11):1554-62.

21. Jara ME. Evans osteotomy complications. Foot Ankle Clin. 2017;22(3):573-85.

22. Tien TR, Parks BG, Guyton GP. Plantar pressures in the forefoot after lateral column lengthening: a cadaver study comparing the Evans osteotomy and calcaneocuboid fusion. Foot Ankle Int. 2005:26(7):520-5.

23. Demetracopoulos CA, Nair P, Malzberg A, Deland JT. Outcomes of a stepcut lengthening calcaneal osteotomy for adult-acquired flatfoot deformity. Foot Ankle Int. 2015;36(7):749-55.

24. Chong DY, Macwilliams BA, Hennessey TA, Teske N, Stevens PM. Prospective comparison of subtalar arthroereisis with lateral column lengthening for painful flatfeet. J Pediatr Orthop B. 2015;24(4):345-53.

25. Ellis SJ, Yu JC, Johnson AH, Elliott A, O'Malley M, Deland J. Plantar pressures in patients with and without lateral foot pain after lateral column lengthening. J Bone Joint Surg Am. 2010;92(1):81-91.

26. Mourkus H, Prem H. Double calcaneal osteotomy with minimally invasive surgery for the treatment of severe flexible flatfeet. Int Orthop. 2018:42(9):2123-9.

27. Xu Y, Cao YX, Li XC, Zhu Y, Xu XY. Double calcaneal osteotomy for severe adolescent flexible flatfoot reconstruction. J Orthop Surg Res. 2017;12(1):153

28. Gehrig LB. CORR insights ${ }^{\circledR}$ : incidence and risk factors of allograft bone failure after calcaneal lengthening. Clin Orthop Relat Res. 2015;473(5):1775-6

29. Evans D. Calcaneo-valgus deformity. J Bone Joint Surg Br. 1975;57(3):270-8.

30. Mohamed KMS, Fenelon C, Galbraith JG, D'Souza LG. Obtaining local bone graft for Evans calcaneal osteotomy in pes planovalgus deformity correction. Foot Ankle Surg. 2017;23(3):208-10.

31. Myerson MS, Neufeld SK, Uribe J. Fresh-frozen structural allografts in the foot and ankle. J Bone Joint Surg Am. 2005;87(1):113-20.

32. Rhodes J, Mansour A, Frickman A, Pritchard B, Flynn K, Pan Z, et al. Comparison of allograft and bovine xenograft in calcaneal lengthening osteotomy for flatfoot deformity in cerebral palsy. J Pediatr Orthop. 2017;37(3):e202-8.

33. Muller MA, Frank A, Briel M, Valderrabano V, Vavken P, Entezari V, et al. Substitutes of structural and non-structural autologous bone grafts in hindfoot arthrodeses and osteotomies: a systematic review. BMC Musculoskelet Disord. 2013;14:59. https://doi.org/10.1186/1471-2474-14-59.

34. Godette GA, Kopta JA, Egle DM. Biomechanical effects of gamma irradiation on fresh frozen allografts in vivo. Orthopedics. 1996;19(8):649-53.

35. Nguyen $\mathrm{H}$, Morgan DA, Forwood MR. Sterilization of allograft bone: effects of gamma irradiation on allograft biology and biomechanics. Cell Tissue Bank. 2007;8(2):93-105.

36. Glancy GL, Brugioni DJ, Eilert RE, Chang FM. Autograft versus allograft for benign lesions in children. Clin Orthop Relat Res. 1991;262:28-33.

37. Glenn RE Jr, McCarty EC, Potter HG, Juliao SF, Gordon JD, Spindler KP. Comparison of fresh osteochondral autografts and allografts: a canine model. Am J Sports Med. 2006;34(7):1084-93.

38. Mahan KT, Hillstrom HJ. Bone grafting in foot and ankle surgery. A review of 300 cases. J Am Podiatr Med Assoc. 1998;88(3):109-18.

39. Templin D, Jones $K$, Weiner DS. The incorporation of allogeneic and autogenous bone graft in healing of lateral column lengthening of the calcaneus. J Foot Ankle Surg. 2008:47(4):283-7.

40. Dell PC, Burchardt H, Glowczewskie FP Jr. A roentgenographic, biomechanical, and histological evaluation of vascularized and nonvascularized segmental fibular canine autografts. J Bone Joint Surg Am. 1985;67(1):105-12.

41. Einhorn TA, Majeska RJ, Rush EB, Levine PM, Horowitz MC. The expression of cytokine activity by fracture callus. J Bone Miner Res. 1995;10(8):1272-81

42. Zerbo IR, de Lange $G L$, Joldersma M, Bronckers AL, Burger EH. Fate of monocortical bone blocks grafted in the human maxilla: a histological and histomorphometric study. Clin Oral Implants Res. 2003;14(6):759-66.

43. Clarke A, Flowers MJ, Davies AG, Fernandes J, Jones S. Morbidity associated with anterior iliac crest bone graft harvesting in children undergoing orthopaedic surgery: a prospective review. J Child Orthop. 2015:9(5):411-6.

44. Wang Q, Whittle M, Cunningham J, Kenwright J. Fibula and its ligaments in load transmission and ankle joint stability. Clin Orthop Relat Res. 1996;(330):261-70. https://doi.org/10.1097/00003086-199609000-00034.

45. Bozkurt M, Yavuzer G, Tonuk E, Kentel B. Dynamic function of the fibula. Gait analysis evaluation of three different parts of the shank after fibulectomy: proximal, middle and distal. Arch Orthop Trauma Surg. 2005:125(10):713-20.

46. Brinker MR, O'Connor DP. Partial fibulectomy for symptomatic fibular nonunion. Foot Ankle Int. 2010;31(6):542-6.

47. Lee EH, Goh JC, Helm R, Pho RW. Donor site morbidity following resection of the fibula. J Bone Joint Surg Br. 1990;72(1):129-31.

48. Banwell H, Paris M, Mackintosh S, Williams C. Paediatric flexible flat foot: how are we measuring it and are we getting it right? A systematic review. J Foot Ankle Res. 2018:11:21.

\section{Publisher's Note}

Springer Nature remains neutral with regard to jurisdictional claims in published maps and institutional affiliations.

Ready to submit your research? Choose BMC and benefit from:

- fast, convenient online submission

- thorough peer review by experienced researchers in your field

- rapid publication on acceptance

- support for research data, including large and complex data types

- gold Open Access which fosters wider collaboration and increased citations

- maximum visibility for your research: over 100M website views per year

At BMC, research is always in progress.

Learn more biomedcentral.com/submissions 